archives-ouvertes

\title{
Covalent Adaptable Networks Using $\beta$-Amino Esters as Thermally Reversible Building Blocks
}

\author{
Christian Taplan, Marc Guerre, Filip Du Prez
}

\section{To cite this version:}

Christian Taplan, Marc Guerre, Filip Du Prez. Covalent Adaptable Networks Using $\beta$-Amino Esters as Thermally Reversible Building Blocks. Journal of the American Chemical Society, American Chemical Society, 2021, 143 (24), pp.9140-9150. 10.1021/jacs.1c03316 . hal-03259626

\section{HAL Id: hal-03259626 \\ https://hal.archives-ouvertes.fr/hal-03259626}

Submitted on 6 Jul 2021

HAL is a multi-disciplinary open access archive for the deposit and dissemination of scientific research documents, whether they are published or not. The documents may come from teaching and research institutions in France or abroad, or from public or private research centers.
L'archive ouverte pluridisciplinaire HAL, est destinée au dépôt et à la diffusion de documents scientifiques de niveau recherche, publiés ou non, émanant des établissements d'enseignement et de recherche français ou étrangers, des laboratoires publics ou privés. 


\section{Covalent adaptable networks using beta-amino}

esters as thermally reversible building blocks

Christian Taplan ${ }^{a}$, Marc Guerre ${ }^{a, b}$, and Filip E. Du Prez $* a$

${ }^{a}$ Polymer Chemistry Research Group, Center of Macromolecular Chemistry (CMaC), Department of Organic and Macromolecular Chemistry, Faculty of Science, Ghent University, Krijgslaan 281 S4-bis, Ghent B-9000, Belgium

${ }^{\text {b }}$ Laboratoire des IMRCP, Université de Toulouse, CNRS UMR5623, Université Paul Sabatier, 118 route de Narbonne, 31062 Toulouse Cedex 9, France

KEYWORDS. Covalent adaptable networks, beta-amino esters, dynamic aza-Michael, transesterification, recyclable thermoset 


\begin{abstract}
In this study, beta-amino esters, prepared by the aza-Michael addition of an amine to an acrylate moiety, are investigated as building blocks for the formation of dynamic covalent networks. While such amino esters are usually considered as thermally, non-dynamic adducts, the kinetic model studies presented here show that dynamic covalent exchange occurs both via dynamic aza-Michael reaction and catalyst-free transesterification. This knowledge is transferred to create beta-amino ester-based covalent adaptable networks (CANs) with co-existing dissociative and associative covalent dynamic exchange reactions. The ease, robustness and versatility of this chemistry is demonstrated by using a variety of readily available multifunctional acrylates and amines. The presented CANs are reprocessed either via a dynamic aza-Michael reaction or a catalyst-free transesterification in the presence of hydroxyl moieties. This results in reprocessable, densely crosslinked materials with a glass transition temperature $\left(\mathrm{T}_{\mathrm{g}}\right)$ ranging from $-60^{\circ} \mathrm{C}$ to $90^{\circ} \mathrm{C}$. Moreover, even for the low $\mathrm{T}_{\mathrm{g}}$ materials, a high creep resistance was demonstrated at elevated temperatures up to $80^{\circ} \mathrm{C}$. When additional beta-hydroxyl group-containing building blocks are applied during the network design, an enhanced neighboring group participation effect allows to reprocess materials up to ten times at $150^{\circ} \mathrm{C}$ within 30 minutes while maintaining their material properties.
\end{abstract}




\section{INTRODUCTION}

Current times are often referred to as the plastic era in which a life without polymer materials is unimaginable. However, plastic pollution accompanying the technological advancements is becoming an ever increasing issue. ${ }^{1,2}$ In particular, one important polymer material category, referred to as thermosetting materials, which was intentionally designed to be dimensionally stable and to provide high chemical and mechanical durability, is nowadays in the focus of research towards sustainable end-of-life options. Indeed, despite their superior properties compared to thermoplastics, thermosets are very challenging to recycle and consequently, often simply go to waste or are being incinerated. ${ }^{3}$ Therefore, the scientific community proposed strategies to implement reversible covalent bonds into the thermoset compositions, which allowed the creation of three-dimensional covalent networks, yet with reversible crosslinking points making reprocessing upon a stimulus possible..$^{4-6}$

The introduction of covalent adaptable networks (CANs) followed a tradition in science and chemistry to consider molecules and reactions from the past as inspiration to solve current problems and push scientific boundaries. ${ }^{7}$ In fact, already decades ago, it was reported that crosslinked rubbers using disulfide bonds and silyl ethers showed thermally activated dynamic behavior and thus enabled the creation of reprocessable covalent networks.${ }^{8,9}$ In more recent years, scientists put much research effort in exploring additional covalent dynamic reactions. ${ }^{10-12}$ For CANs, applicable dynamic covalent reactions are for instance reversible cycloadditions ${ }^{4,13,14}$, disulfide $^{15-18}$ or silyl ether exchange ${ }^{15-17,19,20}$, transalkylation ${ }^{21-23}$, trans(thio)esterification ${ }^{6,24,25}$, transamination ${ }^{26-31}$ of various reactive centers and others ${ }^{32-37}$. 
Many of those chemistry platforms have also been highlighted in recent reviews. ${ }^{38-42}$ Some of them apply concepts of internal catalysis or neighboring group participation (NGP) to accelerate or enable exchange in the first place. ${ }^{43}$ This was for instance applied in the context of the aforementioned silyl ether exchange by using a gamma-positioned amino-moiety ${ }^{19}$, and also for transesterifications, by leveraging a beta-hydroxyl group. ${ }^{6}$ Also, introducing a carboxylic or a sulfonic acid group in proximity of an ester group was found to promote a dissociative transesterification mechanism when terephthalate esters were applied. ${ }^{44,45}$ Modifying the nucleophile in the exchange reaction by making using of beta-amino modified alcohols also allowed to tailor the dynamic behavior. ${ }^{46}$

Two co-existing mechanistic pathways were reported when thiols were used to create thioesters, i.e. an associative and dissociative one. ${ }^{47}$ Other chemical reactions allow for two co-existing mechanistic pathways ${ }^{26}$, making use of different exchange chemistries separately ${ }^{48}$ or combining dissociative with associative exchange reactions elegantly using thiols. ${ }^{49,50}$ Yet, combining associative and dissociative dynamic covalent chemistries in a straightforward fashion is rather rare. Recently, Dichtel and co-worker raised the question whether the use of a solely associative exchange mechanism is desirable in view of material design constraints to meet current processing challenges. ${ }^{51}$

In this context, here a strategy is presented based on the aza-Michael addition of amines to acrylates (Scheme 1). First, the created activated esters promote catalyst-free transesterification with alcohol groups as associative exchange mechanism, with the advantage of maintaining crosslinking points and a gradual decrease in viscosity. In addition, the formed aza-Michael adducts allow for a reversible, dissociative breaking point on the electrophilic side of the dynamic 
unit. All of this is achieved in a straightforward fashion and thus provides an opportunity to use a myriad of readily available acrylate, amine and alcohol functionalities.

Scheme 1. Schematic display of an aza-Michael addition between amines and acrylates with the formation of a beta-amino ester that provides possibilities for associative and dissociative covalent dynamic chemistries.
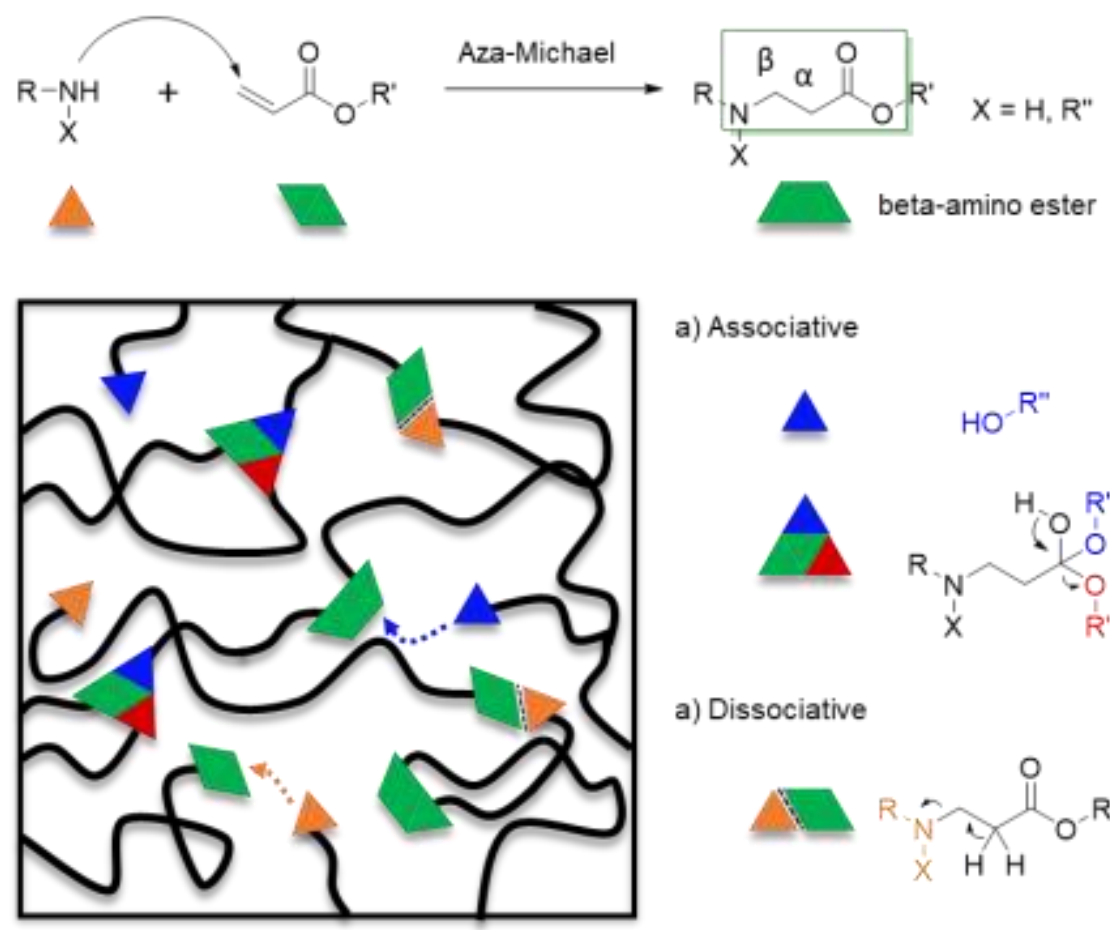

a) Associative

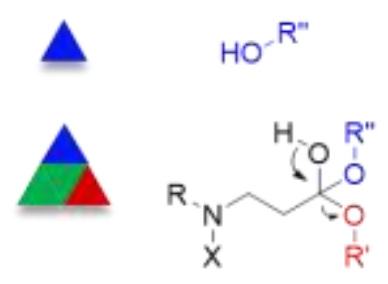

a) Dissociative

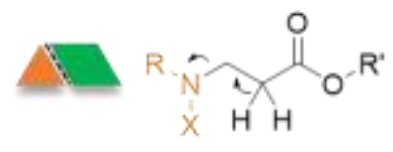

The aza-Michael reaction was widely explored and studied in the context of biomaterials and investigated as for instance degradable polymer materials, for gene-delivery or as precursors for thermosetting resins. ${ }^{52-56}$ Yet interestingly, apart from applying a specifically designed crosslinker $^{57}$, the aza-Michael reaction is usually considered to create permanent bonds in bulk materials and was applied for creating permanently crosslinked reference materials. ${ }^{58}$ Hence, to the best of our knowledge, beta-amino esters were not explored in CANs despite their vast application potential. 


\section{RESULTS}

\section{Model reactions of beta-amino esters}

The first research question was to investigate whether a beta-amino ester can undergo thermally activated dynamic covalent exchange and by which mechanisms this could occurred. For this purpose, $N$-methylbutylamine was reacted with 2-ethylhexyl acrylate to form 2-ethylhexyl 3(butyl(methyl)amino)-propanoate (1) (Figure 1 and Figure S1). This model compound 1 was obtained with a $95 \%$ yield after purification. Afterwards, kinetic experiments were conducted in bulk at various temperatures in the presence of an excess of either benzylalcohol or benzylacrylate, to check for transesterification or dynamic aza-Michael reaction, respectively (Figure 1). This excess allowed to push the system kinetically to a pseudo first-order reaction, so that linearity during the first time points, from which the reaction constants are obtained, was maintained.

When monitoring thermally activated transesterification, the beta-amino ester $\mathbf{1}$ was combined with twelve equivalents of benzylalcohol (reaction 1 in Figure 1a). This reaction was monitored via ${ }^{1} \mathrm{H}$ NMR by following the disappearance of the signal at $3.91 \mathrm{ppm}$ belonging to $\mathbf{1}$ and the appearance of the signal at $3.42 \mathrm{ppm}$ attributed to the newly formed 2-ethylhexylalcohol. The full NMR spectra corresponding to the kinetic study at $100^{\circ} \mathrm{C}$ are provided in the supporting information (Figure S2). Notably, the reappearance of the proton signals between $5.70 \mathrm{ppm}$ and $6.30 \mathrm{ppm}$, corresponding to the acrylate of the respective amino-ester, is detected and pointing to a thermally reversible behavior of the aza-Michael-adduct (vide infra). Monitoring different temperatures, ranging from 80 to $140^{\circ} \mathrm{C}$, resulted in a kinetic plot that demonstrates the possibility for the beta-amino ester 1 to undergo thermally activated, catalyst-free transesterification (Figure $1 \mathrm{~b}$ and Figure S4a). 
a)
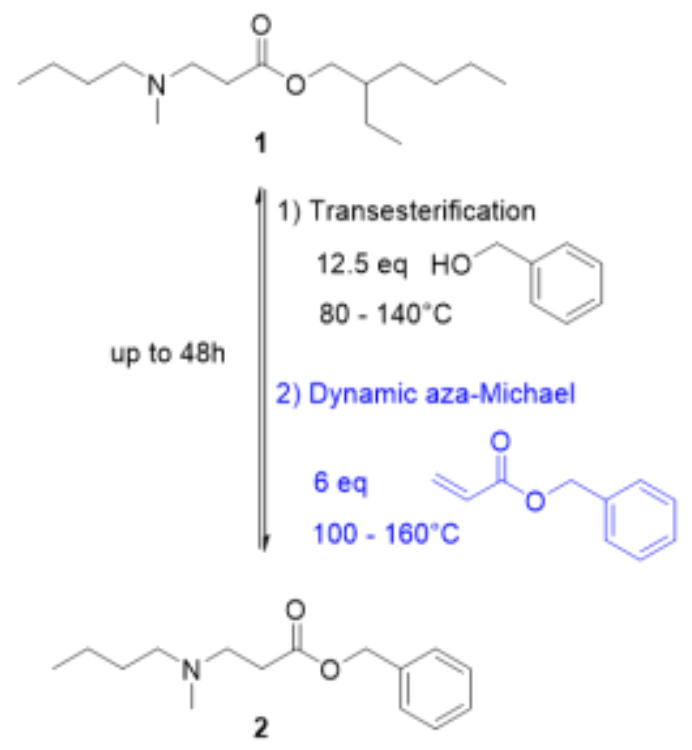

b)

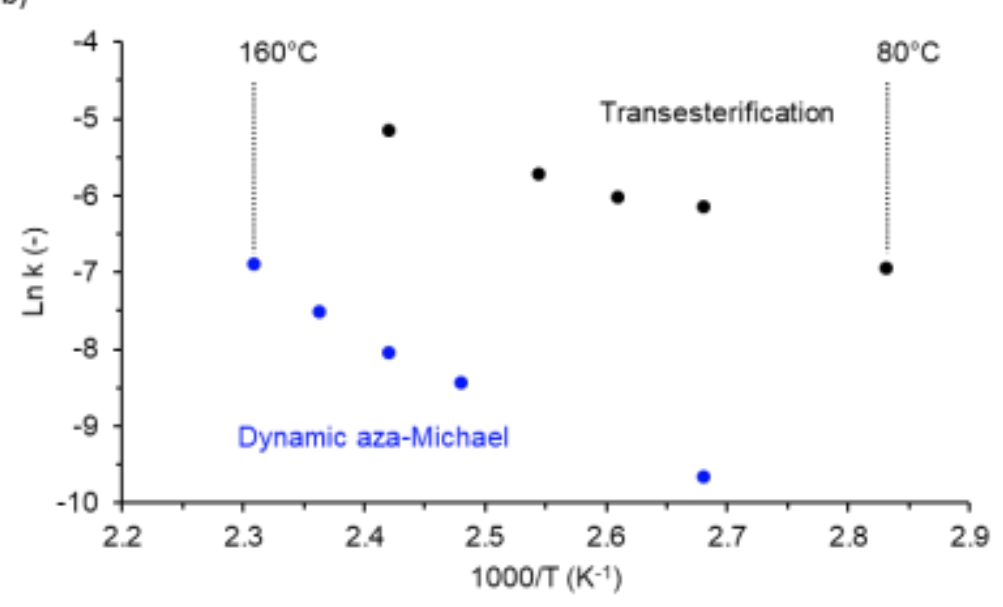

Figure 1. (a) Reaction scheme describing the catalyst-free dynamic exchange with (1) the transesterification of the beta-amino ester 1 with benzylalcohol and (2) the dynamic (retro) azaMichael reaction with benzylacrylate. (b) Arrhenius plots of the monitored reactions obtained by following the decay of $\mathbf{1}$ as a function of time at each of the investigated temperatures.

Furthermore, because $\mathbf{1}$ provides a tertiary amine and upon dissociation also a secondary amino moiety, for which a catalytic effect was earlier described to catalyze the transesterification for epoxy networks, ${ }^{59}$ the transesterification of $\mathbf{1}$ was tested in the presence of either a tertiary or a 
secondary amine as external catalyst. Therefore, $5 \mathrm{~mol} \%$ of $N, N$-diisopropylethylamine (DIPEA) or dibutylamine was added to the reaction mixture and the reaction was monitored at $120^{\circ} \mathrm{C}$. The obtained reaction rates were not found to be strikingly different in the presence of these catalysts, thus not justifying the use of an external catalyst (Figure S3).

Since the appearance of the acrylate signals was detected at $100^{\circ} \mathrm{C}$ in the original model study, in a next step the possibility for the beta-amino ester $\mathbf{1}$ to undergo a dynamic aza-Michael reaction was investigated in a temperature window from $100^{\circ} \mathrm{C}$ to $160^{\circ} \mathrm{C}$ (Figure S5). In order to target the same exchange reaction product $\mathbf{2}$, the reaction was conducted with benzylacrylate. Yet, to avoid the influence of the acrylates' homopolymerization at such elevated temperatures, the amount of benzylacrylate was decreased to six equivalents. In the monitored temperature window, the exchange rate to form beta-amino ester $\mathbf{2}$ appeared to be slower than via the transesterification mechanism (Fig. $1 \mathrm{~b}$ and Fig. S4b). This slow exchange rate of the aza-Michael reaction might be explained by the stability of the adduct, originating from the addition of an amine to an acrylate. At lower temperatures, the readily formed adduct is favored, hence dynamic exchange is unlikely, while at increased temperatures the equilibrium of the (retro) aza-Michael reaction is shifted to the dissociated state, as expected for an addition-elimination type of dynamic covalent exchange reactions. ${ }^{42}$ However, the exchange via the dynamic aza-Michael reaction follows a higher temperature dependency, as also expressed by the activation energies of $35 \pm 2 \mathrm{~kJ} \cdot \mathrm{mol}^{-1}$ and $75 \pm 6 \mathrm{~kJ}_{\mathrm{mol}}{ }^{-1}$ calculated for the monitored transesterification and dynamic aza-Michael reaction, respectively (Figure $1 \mathrm{~b}$ ). Interestingly, while the exchange rates are very slow at $100^{\circ} \mathrm{C}$, they become moderately high at higher temperatures with a strong temperature dependence as shown with an Arrhenius plot. The fact that beta-amino esters undergo dynamic bond exchanges at elevated temperatures, both via an associative and dissociative dynamic bond exchange, was 
intriguing and unique in the context of CANs (vide infra) as this would allow for potential coexistence of both mechanisms at material processing temperatures.

\section{Beta-amino esters-based covalent adaptable networks}

This conceptually demonstrated catalyst-free dynamic covalent exchange chemistry was translated to the design of CANs. Therefore, several beta-amino ester-based networks (BAE) were synthesized via the aza-Michael addition of small and macromolecular multifunctional primary amines (4,4'-methylenebis(cyclohexylamine) (MBCA), Jeffamine D2000 and Priamine 1074) with two types of multifunctional, technical grade acrylates (trimethylolpropane triacrylate (TMPTA) and pentaerythritol triacrylate (PTA)) for which the radical stabilizer was not removed (Table 1).

Table 1. Overview of composition and physical properties of beta-amino ester-based CANs.

\begin{tabular}{|c|c|c|c|c|c|c|c|}
\hline CAN & Acrylate & Amine & $\begin{array}{l}\mathrm{T}_{\mathrm{gDSC}}{ }^{\mathrm{a}} \\
\left({ }^{\circ} \mathrm{C}\right)\end{array}$ & $\begin{array}{l}\mathrm{T}_{\mathrm{d}-95 \%}{ }^{\mathrm{b}} \\
\left({ }^{\circ} \mathrm{C}\right)\end{array}$ & $\begin{array}{c}\text { Soluble fraction } \\
\text { (\%) }\end{array}$ & $\begin{array}{c}\text { Swelling degree }{ }^{d} \\
(\%)\end{array}$ & $\begin{array}{c}\mathrm{E}_{\mathrm{a}(\text { flow })} \\
\left(\mathrm{kJ} \cdot \mathrm{mol}^{-1}\right)\end{array}$ \\
\hline BAE-1 & TMPTA & Jeffamine & -57 & 315 & 15 & 455 & $163 \pm 12$ \\
\hline BAE-2 & TMPTA & Priamine & -13 & 275 & 3.0 & 85 & $170 \pm 14$ \\
\hline BAE-3 & TMPTA & MBCA & 62 & 280 & $-{ }^{\mathrm{e}}$ & 45 & $153 \pm 6$ \\
\hline BAE-1-OH & PTA & Jeffamine & -59 & 330 & 5.8 & 295 & $242 \pm 8$ \\
\hline BAE-2-OH & PTA & Priamine & -2 & 300 & 2.4 & 65 & $110 \pm 4$ \\
\hline BAE-3-OH & PTA & MBCA & 93 & 295 & $-{ }^{\mathrm{e}}$ & 15 & $184 \pm 7$ \\
\hline
\end{tabular}


${ }^{a}$ DSC glass transition temperature $\left(\mathrm{T}_{\mathrm{gDSC}}\right),{ }^{\mathrm{b}}$ TGA onset temperatures after $5 \%$ weight $\operatorname{loss}\left(\mathrm{T}_{\mathrm{d}-95 \%}\right),{ }^{\mathrm{c}}$ obtained after Soxhlet extraction for $24 \mathrm{~h}$ in THF, ${ }^{\mathrm{d}}$ obtained after swelling in THF for seven days at rt, ${ }^{\mathrm{e}}$ no soluble fraction detectable.

PTA provided additional hydroxyl groups, which allowed the investigation of the BAEs with or without pending $\mathrm{OH}$-groups (referred to as $\mathrm{BAE}-\mathrm{X}-\mathrm{OH}$ and BAE-X, respectively). Network synthesis was conducted in bulk, targeting stoichiometric amounts of amine protons to acrylates (Figure 2 a).
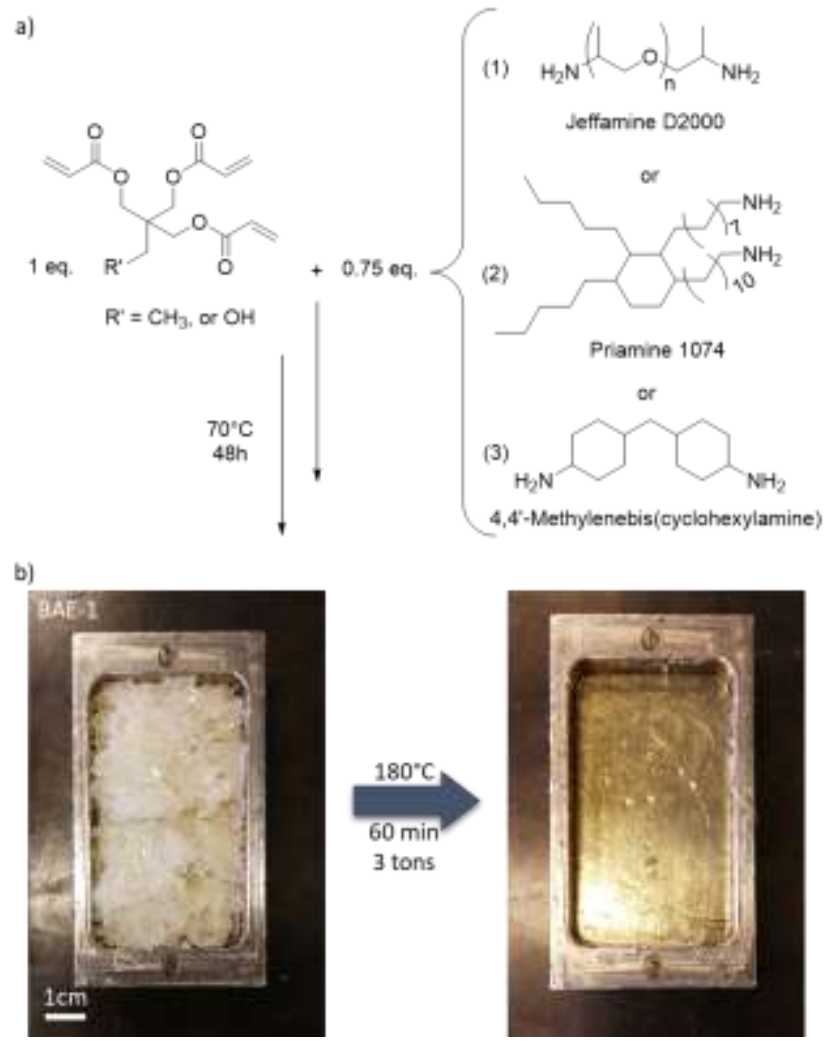

Figure 2. (a) Reaction scheme of the formation of beta-amino ester networks. (b) A reprocessed TMPTA/Jeffamine D2000 (BAE-1) sample, leveraging the retro aza-Michael reaction as covalent dynamic chemistry. 
The mixtures were cured at $70^{\circ} \mathrm{C}$ for $72 \mathrm{~h}$ for Jeffamine D2000 (BAE-1, BAE-1-OH) and $48 \mathrm{~h}$ for Priamine 1074 (BAE-2, BAE-2-OH) and MBCA (BAE-3, BAE-3-OH) containing networks (Table 1). The conversion was checked via ATR-FTIR (Figure S10) and network formation verified via swelling tests and Soxhlet extraction with THF (Table 1). Swelling ratios in THF increased when lowering the crosslinking density and ranged from $455 \%$ (BAE-1) to $15 \%$ (BAE3-OH). As expected, when considering hydrogen bonding, the additional hydroxyl groups in PTAbased CANs consistently resulted in lower swelling degrees. In addition, even for Jeffamine-based materials showing high swelling ratios, relatively low soluble fractions were obtained. Moreover, no soluble fraction was detected for BAE-3 and BAE-3-OH, which is ascribed to the high crosslinking density of these materials.

Each of these polymer networks were used to demonstrate the possibility of creating thermally reprocessable crosslinked materials on the basis of both catalyst-free dynamic transesterification and dynamic aza-Michael reaction. Hence, they were compression molded into a plate, exemplified for BAE-1 (Figure 2b) and BAE-3 (Figure S7) at $180^{\circ} \mathrm{C}$, a temperature well below the degradation temperature, within one hour and with an applied pressure of two to four tons. A reference network, obtained by UV-cured pentaerythritol triacrylate in the absence of beta-amino esters, were not reprocessable, even after two hours of hot-pressing at $180^{\circ} \mathrm{C}$ (Figure S8).

The reprocessable materials displayed $\mathrm{T}_{\mathrm{g}}$ from $-60^{\circ} \mathrm{C}$ to $90^{\circ} \mathrm{C}$, as measured by differential scanning calorimetry (DSC) (Table 1 and Figure S9). It should be noted that PTA based CANs displayed a higher $\mathrm{T}_{\mathrm{g}}$ than their non-hydroxyl group containing counterpart CANs based on TMPTA, as expected from the additional hydrogen bond interactions. TGA-analysis displayed a degradation onset temperature $\left(\mathrm{T}_{\mathrm{d}-95 \%}\right)$ in a range of $275^{\circ} \mathrm{C}$ to $330^{\circ} \mathrm{C}$ (Table 1, Figure S10-S11), well beyond the processing temperature. Besides, the multifunctional amine compounds with a 
boiling point beyond processing temperatures are expected to remain part of the network. This is exemplified with BAE-3-OH $\left(\mathrm{T}_{\mathrm{d}-95 \%}=295^{\circ} \mathrm{C}\right)$, in which the isothermal mass loss was determined to be less than $1.5 \%$ weight loss after one hour at $200^{\circ} \mathrm{C}$ (Figure 3, black line).

a)
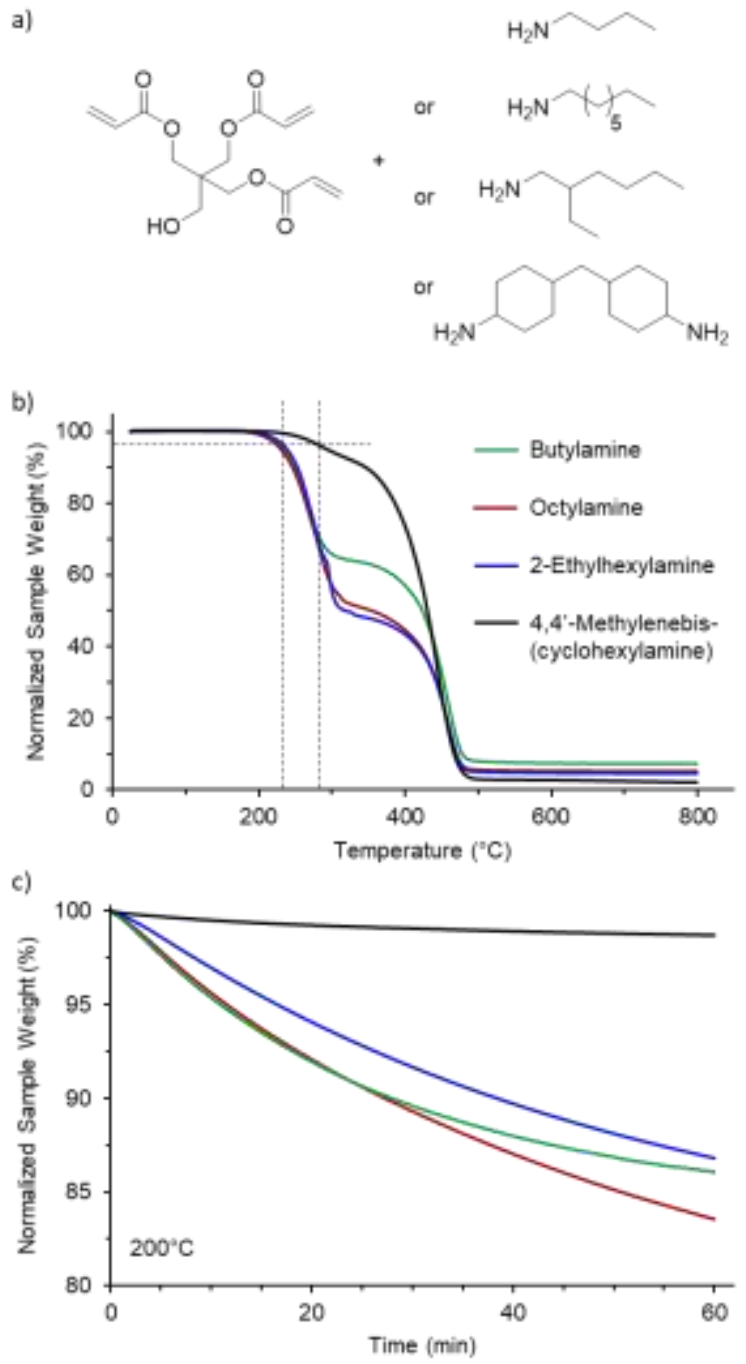

Figure 3. (a) Aza-Michael-based polymer networks originating from PTA and different amines. (b) TGA showing an earlier onset temperature after $5 \%$ wt. loss between $230-240^{\circ} \mathrm{C}$ for butyl-, octyl-, and 2-ethylhexylamine in comparison to the less volatile $4,4^{\prime}$ 'methylenebis(cyclohexylamine) $\left(295^{\circ} \mathrm{C}\right)$. (c) Representation of the weight loss versus time of the polymer networks under isothermal conditions at $200^{\circ} \mathrm{C}$ in the course of one hour. 
Moreover, when low molecular mass primary amines, i.e. butylamine, octylamine and 2ethylhexylamine were used as reaction partner to form dynamic beta-amino ester networks, they did not only show an earlier onset temperature in a TGA temperature ramp (Figure 3b) but also demonstrated a dramatically higher amount of mass loss under similar isothermal conditions (Figure 3c). This observation confirms the retro aza-Michael reaction occurring in such bulk materials, as demonstrated in the model study described above.

\section{Dynamic properties of beta-amino ester based materials}

Rheological characterization of the created CANs was performed to investigate the dynamic material properties. Firstly, when stress relaxation experiments were performed, it was observed that each of the networks displayed stress relaxation at $180^{\circ} \mathrm{C}$ (Figure S12-S13). Additionally, a higher exchange rate - linked to faster stress relaxation - was detected, when a hydroxyl group bearing acrylate (i.e. PTA) was used compared to TMPTA. Indeed, in the herein presented system, dynamic aza-Michael and transesterification were concurrently occurring at elevated temperatures, and elastomeric materials with pendent hydroxyl groups displayed a faster exchange rate, as exemplified with BAE-1 (Figure 4a). This is in line with reported studies, which showed that a synergetic effect is typically observed when multiple dynamic chemistries are implemented in a material. ${ }^{18,48}$ Besides, when stress relaxation experiments were performed at different temperatures for the obtained materials, a high temperature dependence was observed, resulting in a flow activation energy $\left(\mathrm{E}_{\mathrm{a}(\mathrm{flow})}\right)$ of 110 to $240 \mathrm{~kJ} \cdot \mathrm{mol}^{-1}$ (Table 1). Such high temperature dependent dynamic behavior favors the creation of dynamic, yet, creep resistant elastomers ${ }^{41}$, as very recently reported with addition-type reprocessable elastomers. ${ }^{60}$ 

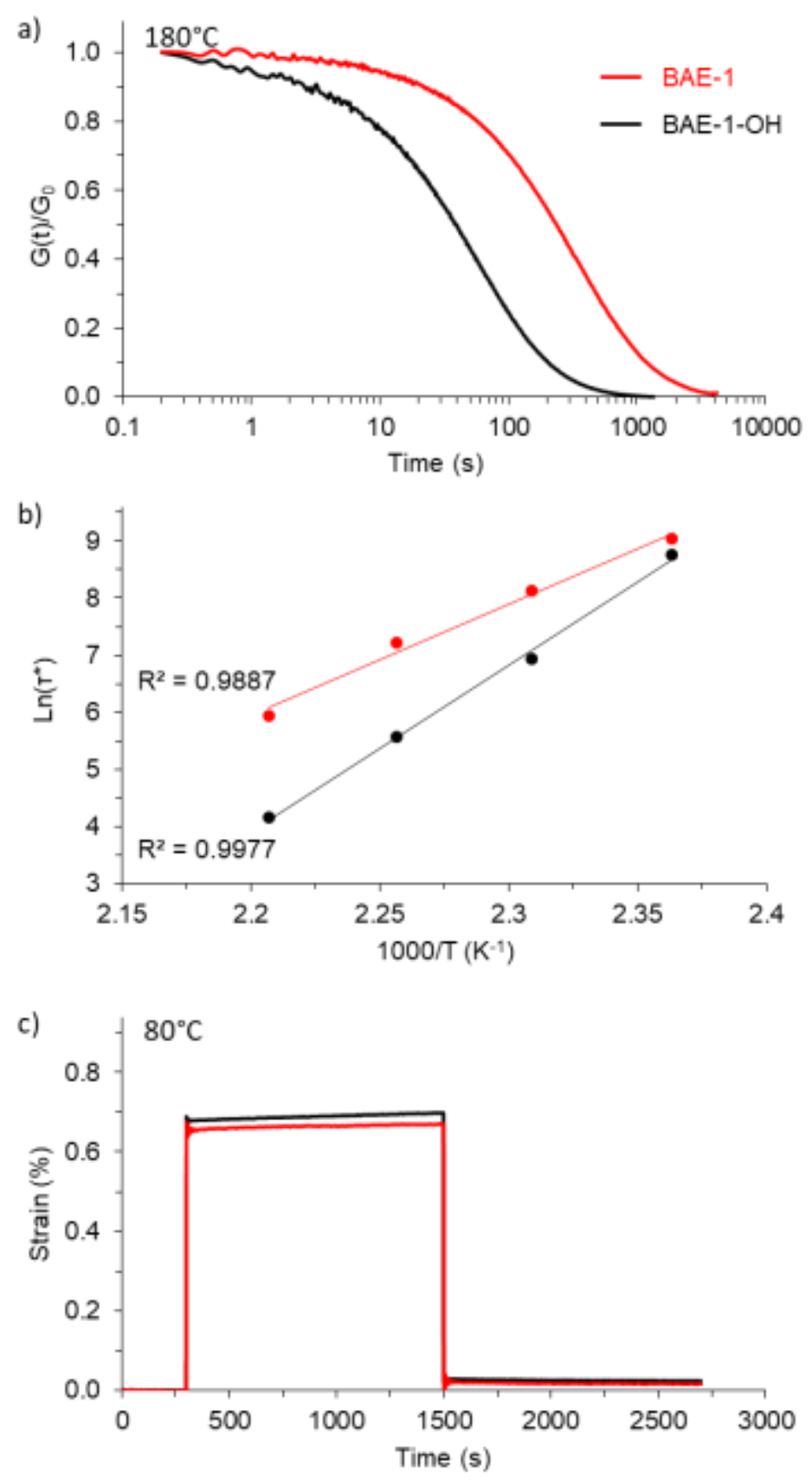

Figure 4 (a) Stress relaxation of elastomeric dynamic networks based on Jeffamine D2000 BAE-1 (red) and BAE-1-OH (black) at $180^{\circ} \mathrm{C}$. (b) Respective Arrhenius plot derived activation energy of flow, obtained from measurements at $180^{\circ} \mathrm{C}$ to $150^{\circ} \mathrm{C}$. (c) Creep recovery experiments performed at $80^{\circ} \mathrm{C}$ with a remaining permanent deformation of $0.02 \%$. 
Hence, because of the high activation energy derived from the respective Arrhenius plots (i.e. $163 \pm 12 \mathrm{~kJ} \mathrm{~mol}^{-1}$ and $242 \pm 8 \mathrm{~kJ} \mathrm{~mol}^{-1}$ for BAE-1 and BAE-1-OH, respectively) (Figure 4b), both elastomers demonstrated strong creep resistance at elevated temperatures $\left(50^{\circ} \mathrm{C}\right.$ and $\left.80^{\circ} \mathrm{C}\right)$. Indeed, upon exposure to $2 \mathrm{kPa}$ shear stress for $20 \mathrm{~min}$, the materials displayed merely $\sim 0.01 \%$ $\left(50^{\circ} \mathrm{C}\right)$ and $\sim 0.02 \%\left(80^{\circ} \mathrm{C}\right)$ remaining strain as permanent deformation after a recovery period of $20 \min$ (Figure $4 \mathbf{c}$ and S14).

\section{CANs with a double neighboring group participation effect}

To take this approach a step further, the effect of a double neighboring group participation (NGP) on the exchange rate was investigated. Indeed, in addition to the beta-amino group, which is hypothesized to be responsible for creating an activation of the ester bond via coordination of the alcohol proton and the ester-carbonyl group, a beta-hydroxyl group can be simultaneously introduced. Such a hydroxyl group, in beta position of an ester, was in fact already reported by Leibler and co-workers ${ }^{6}$ in the seminal paper of vitrimers.

Herein, this NGP effect was introduced using a beta-hydroxyl functional bis-acrylate moiety (Figure 5a). While the beta-amino moiety activates the electrophile side of the ester group, the beta-hydroxyl one allows for swift reactivity on the nucleophile side. For the corresponding CANs, further referred to as BPAE materials, bisphenol A glycerolate diacrylate (BPADA) was used in combination with similar amines as for the beta-amino ester networks described above (Table 2). They displayed a $\mathrm{T}_{\mathrm{g}}$ of $-40^{\circ} \mathrm{C}$ (BPAE-1), $30^{\circ} \mathrm{C}$ (BPAE-2) and $70^{\circ} \mathrm{C}$ (BPAE-3), leading to elastomeric as well as rigid polymer samples while being thermally stable beyond $300^{\circ} \mathrm{C}$ (Table 2, Figure S15-S18). 
Table 2. Overview of compositions and physical properties of beta-amino ester-based CANs showing a double NGP effect.

\begin{tabular}{|c|c|c|c|c|c|c|c|}
\hline CAN & Acrylate & Amine & $\begin{array}{l}\mathrm{T}_{\mathrm{gDSC}}{ }^{\mathrm{a}} \\
\left({ }^{\circ} \mathrm{C}\right)\end{array}$ & $\begin{array}{l}\mathrm{T}_{\mathrm{d}-95 \%}{ }^{\mathrm{b}} \\
\left({ }^{\circ} \mathrm{C}\right)\end{array}$ & $\begin{array}{c}\text { Soluble fraction }{ }^{\mathrm{c}} \\
(\%)\end{array}$ & $\begin{array}{c}\text { Swelling degree } \\
\text { (\%) }\end{array}$ & $\begin{array}{c}\mathrm{E}_{\mathrm{a}(\text { flow })} \\
\left(\mathrm{kJ} . \mathrm{mol}^{-1}\right)\end{array}$ \\
\hline BPAE-1 & BPADA & Jeffamine & $-40{ }^{\circ} \mathrm{C}$ & $340^{\circ} \mathrm{C}$ & 14 & 425 & $180 \pm 24$ \\
\hline BPAE-2 & BPADA & Priamine & $30^{\circ} \mathrm{C}$ & $340{ }^{\circ} \mathrm{C}$ & 2.8 & 95 & $121 \pm 7$ \\
\hline BPAE-3 & BPADA & MBCA & $70^{\circ} \mathrm{C}$ & $310^{\circ} \mathrm{C}$ & 5.0 & 90 & $156 \pm 8$ \\
\hline
\end{tabular}

${ }^{\mathrm{a}} \mathrm{T}_{\mathrm{g}}$ obtained from DSC-analysis, ${ }^{\mathrm{b}}$ TGA onset-temperatures after $5 \%$ weight-loss, ${ }^{\mathrm{c}}$ obtained after

Soxhlet-extraction for $24 \mathrm{~h}$ in THF, ${ }^{\mathrm{d}}$ obtained after swelling in THF for seven days at rt.

More specifically, the network composition BPAE-3 (Figure 5a) resulted in a network with a $\mathrm{T}_{\mathrm{g}}$ of $70^{\circ} \mathrm{C}$, a degradation onset temperature of $310^{\circ} \mathrm{C}$ with less than $1 \%$ weight loss over $2 \mathrm{~h}$ at $160^{\circ} \mathrm{C}$ and less than $2 \%$ weight loss over $1 \mathrm{~h}$ at $200^{\circ} \mathrm{C}$ (Figure S19). Moreover, despite having activated ester bonds, BPAE-3 demonstrated to be hydrolytically resistant when immersed in demineralized water up to ten days. This network showed a soluble fraction of less than $1 \%$ while the swelling degree increases with time from $7.2 \%, 11.2 \%$ and $18.1 \%$, after one, four and ten days, respectively.

Because of the accelerated dynamic covalent exchange as a result of the double NGP, reprocessing of the network BPAE-3 was conducted at shorter times and lower temperatures compared to the CANs described earlier, i.e. within 30 minutes at $150^{\circ} \mathrm{C}$ with a pressure of four tons (Figure $\mathbf{5 b}$ ). 
a)

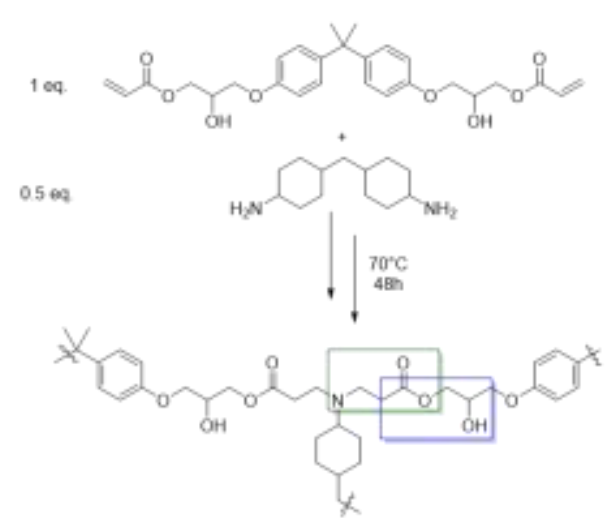

c)
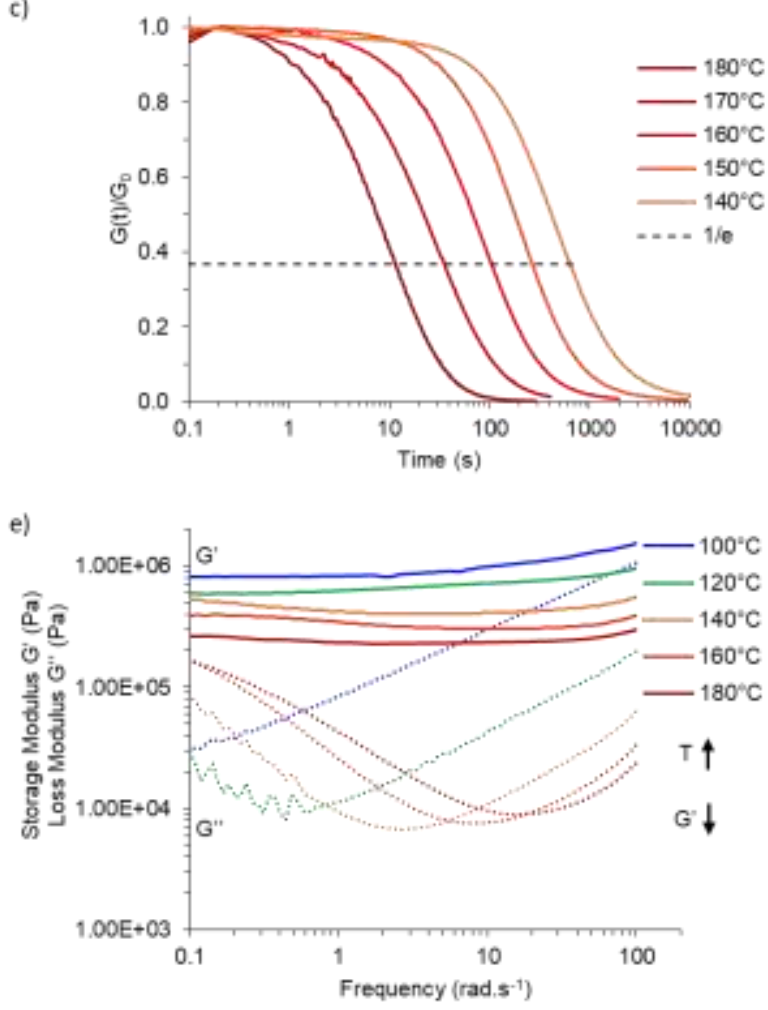

b)

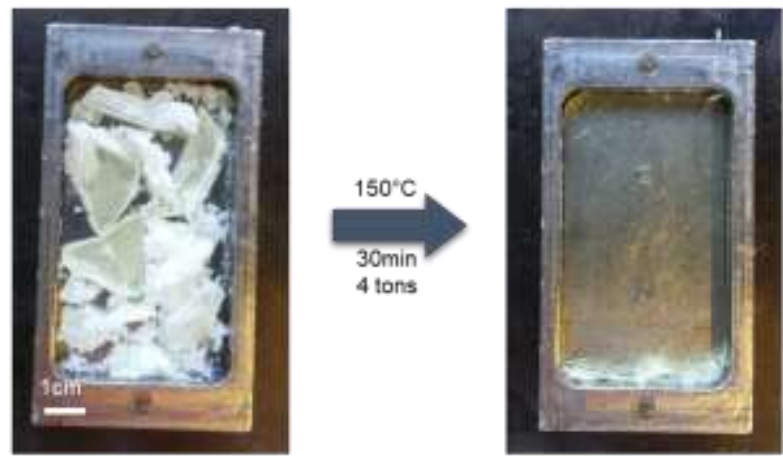

d)

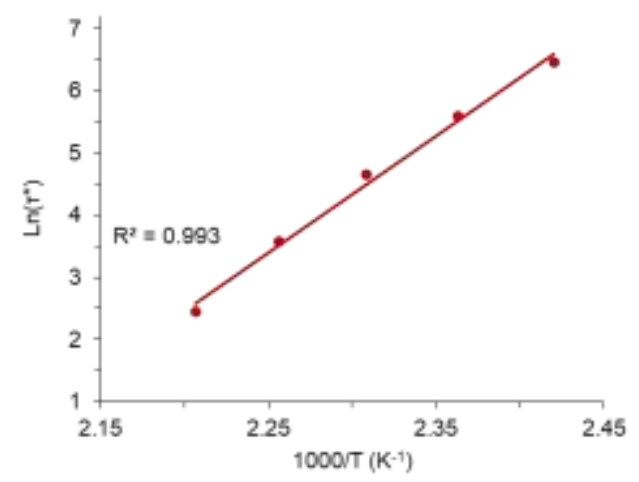

f)

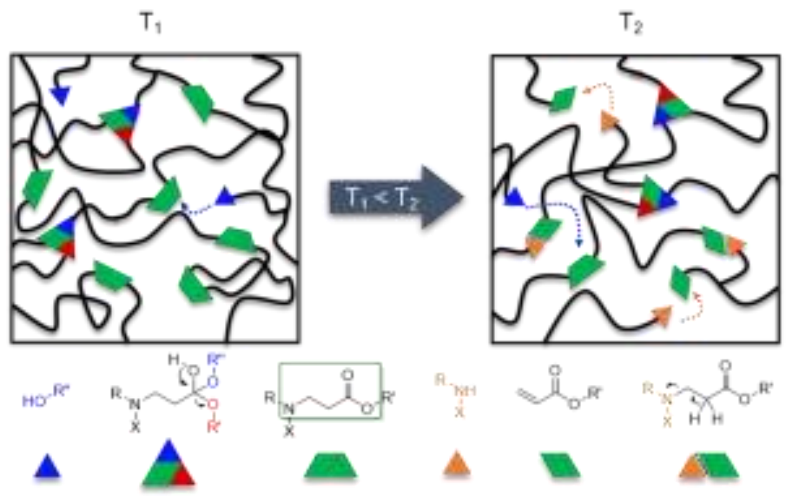

Figure 5. (a) CAN obtained via aza-Michael addition of MBCA to BPADA (BPAE-3), with the potential of two neighboring group effects originating from a beta-amino (green) and a betahydroxyl moiety (blue). (b) Picture of compression molding of BPAE-3. (c) Normalized stress relaxation measurements. (d) Corresponding Arrhenius-plot as a function of 1000/T. (e) Frequency sweep measurement showing a decreased elastic plateau modulus with increased temperature. (f) Scheme for the dissociative and associative dynamic covalent bond exchange. 
When assessing the rheological behavior, stress relaxation measurements demonstrate that the thermally activated network rearrangement allowed for relaxation of the applied stress in the investigated temperature range from 140 to $180^{\circ} \mathrm{C}$ (Figure 5c), with a resulting temperature dependent viscous flow represented by a flow activation energy of $156 \pm 8 \mathrm{~kJ} \mathrm{~mol}^{-1}$ (Figure 5d). This is similarly high as for the above discussed beta-amino ester networks and is again ascribed to originate from a combination of transesterification and dynamic aza-Michael reaction. A frequency sweep of the glassy polymer network (BPAE-3), in combination with the nonnormalized relaxation modulus $(\mathrm{G}(\mathrm{t}))$ obtained from stress relaxation measurements, revealed the co-existence of transesterification while also showing partial decrosslinking. Indeed, the frequency sweep showed a decrease of the material's shear storage modulus (G') upon increasing the temperature while a shift of the anticipated crossover was apparent (Figure 5e). This is in accordance with the observed $\mathrm{G}(\mathrm{t})$ that also decreased with increased temperature (Figure S20), which is indicative for a decrease of crosslinking density in dissociative covalent dynamic polymer networks, ${ }^{61}$ in this particular case related to the dynamic aza-Michael reaction.

The co-existence of both dynamic aza-Michael and transesterification to dissipate applied stress in a material, also resulted in a high flow activation energy for BPAE-1 and BPAE-2 (Figure S21) and demonstrates the broad applicability into different matrices. In combination with the results obtained from the kinetic study (Figure 1), it was concluded that transesterification was likely to occur at temperatures below $120^{\circ} \mathrm{C}$, whereas the dynamic aza-Michael reaction is negligible under these conditions. This is supported by the high creep-resistance at $80^{\circ} \mathrm{C}$ for elastomeric network BPAE-1 (Figure S22). Yet, at elevated temperatures the dynamic aza-Michael reaction mechanism contributed to the overall dynamic covalent exchange related network mobility. Accordingly, in a 
frequency sweep of BPAE-1 upon heating, the elastic plateau modulus remains almost unaltered up to $120^{\circ} \mathrm{C}$, whereas a continuous drop in $\mathrm{G}^{\prime}$ was detected beyond $140^{\circ} \mathrm{C}$ (Figure S23).

\section{Reprocessability}

Next, network BPAE-3 was reprocessed up to ten times with similar conditions (30 minutes compression at $150^{\circ} \mathrm{C}$ with a pressure of four tons), further referred to as $\mathrm{R}_{0}$ up to $\mathrm{R}_{10}$. The network kept its ability for compression molding, showing each time homogeneous, transparent samples, even after up to ten additional reprocessing steps using the aforementioned processing conditions (Figure 6 a, Figure S24). Subsequently, soluble fraction experiments of a piece of the material resulted in soluble fractions of $5.0 \%, 15.2 \%$, and $11.9 \%$ for $\mathrm{R}_{0}, \mathrm{R}_{4}$, and $\mathrm{R}_{10}$ while the swelling degree accounted to $88 \%, 97 \%$ and $108 \%$ respectively. The increase in soluble fraction and swelling ratio is attributed to the partially dissociative nature of the exchange reactions. Reprocessability of the samples was confirmed on behalf of BPAE-3 by examining their stress relaxation properties (Figure S25), represented by their Arrhenius plots (Figure 6 b) as well as frequency sweep experiments (Figure 6 c, Figure S26-S27). In addition, the recorded FTIR spectra and thermal analyses supported the conclusion that the chemical composition and material properties were maintained after ten recycling cycles (Figure S28). 
a)
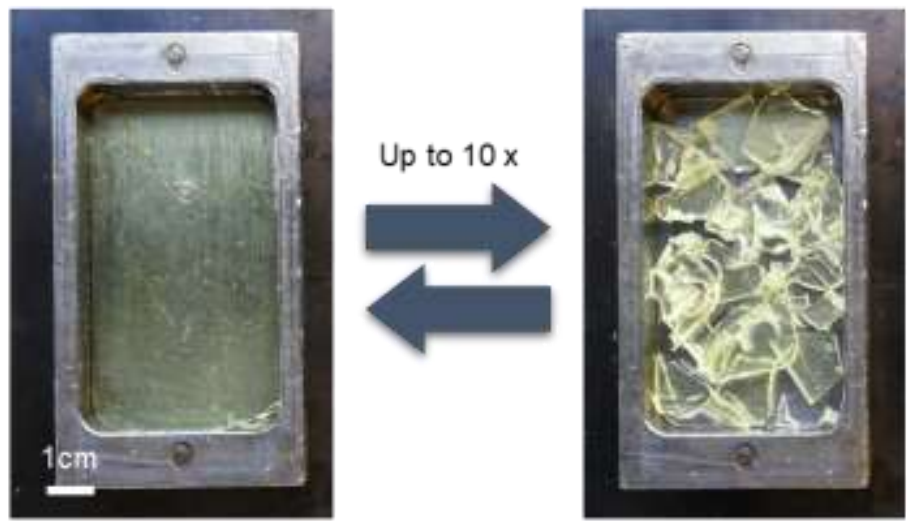

b)
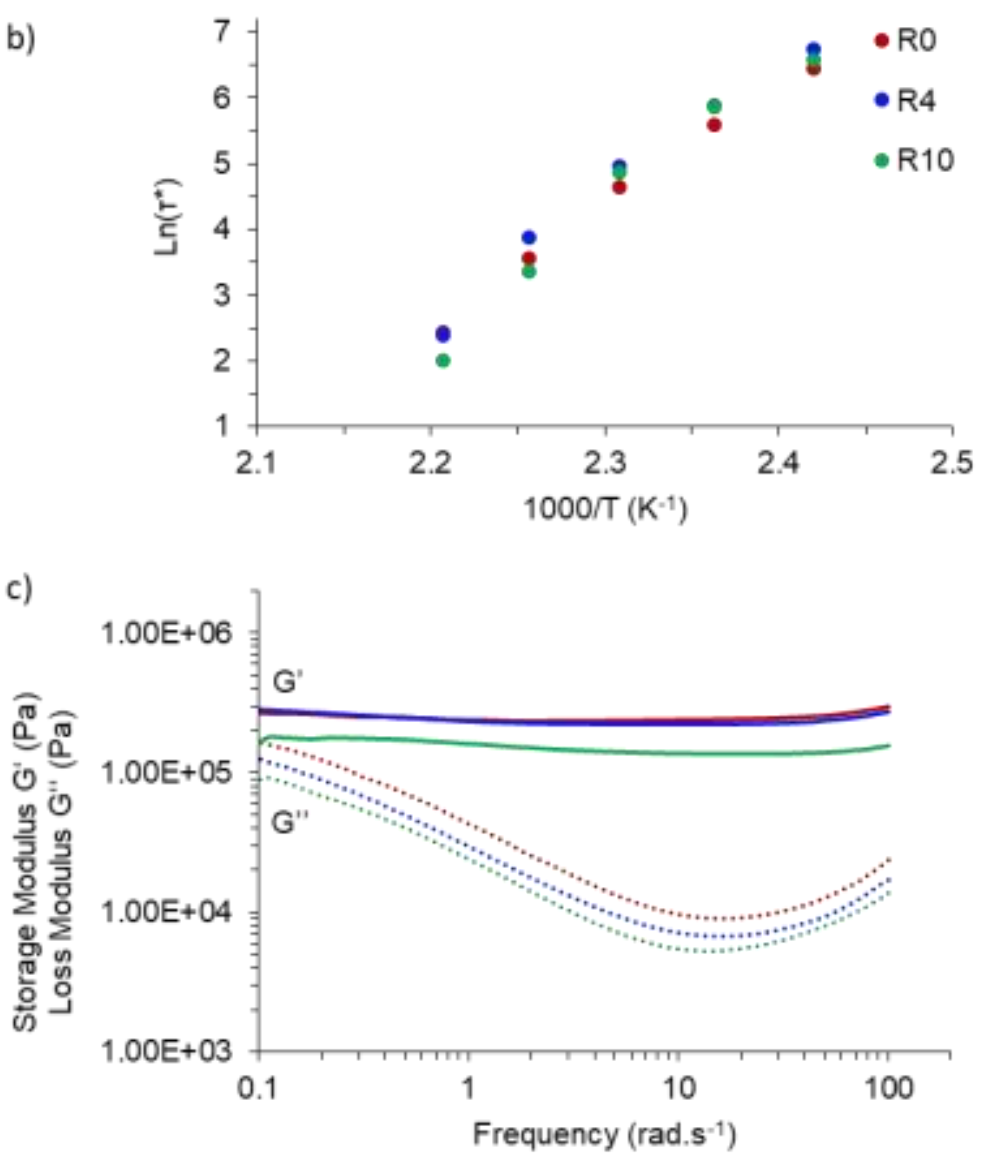
a)

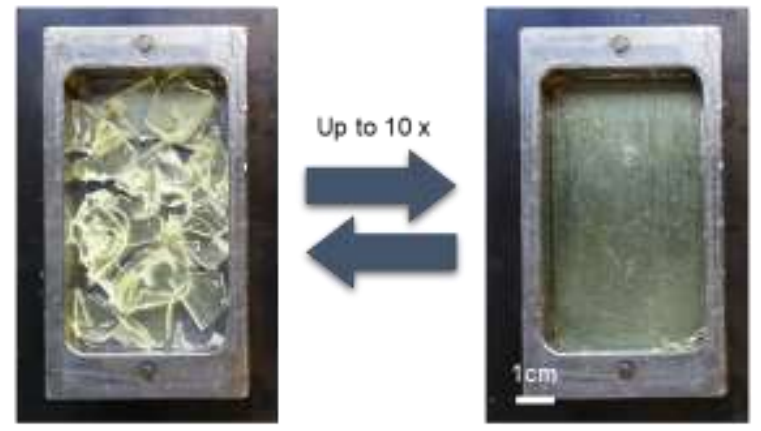

b)
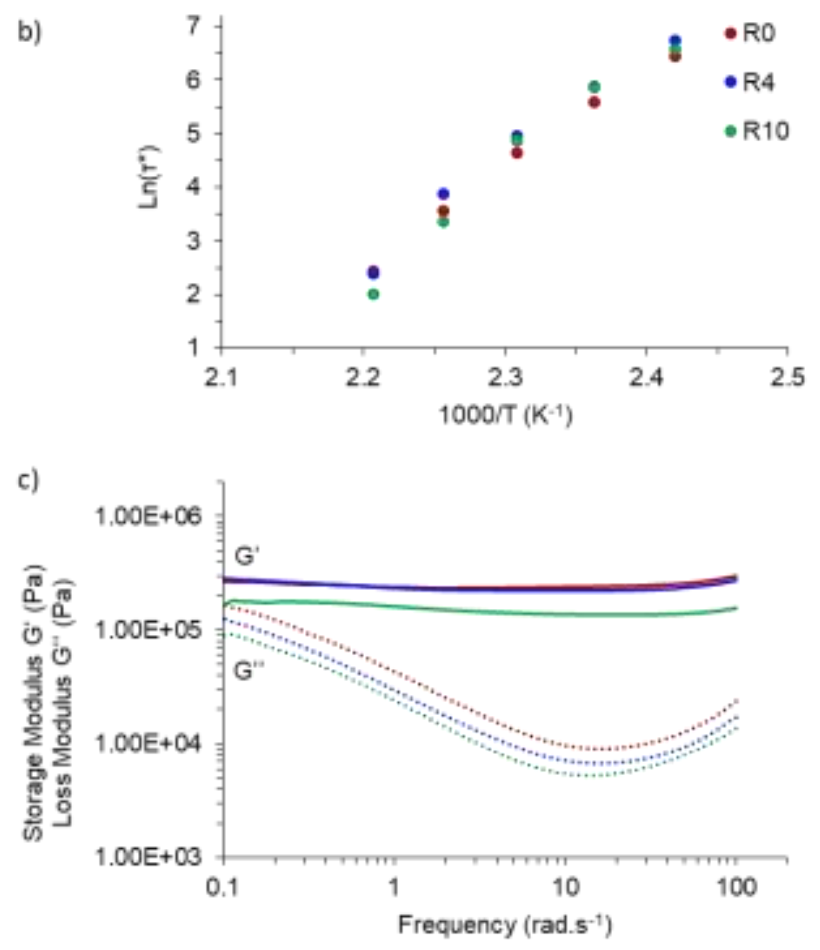

Figure 6. (a) Reprocessing of beta-amino ester network BPAE-3 up to ten times. (b) Arrhenius plot derived from the stress relaxation experiments performed after the initial processing $\left(\mathrm{R}_{0}(\mathrm{red})\right)$ as well as four- and ten-times reprocessing ( $\mathrm{R}_{4}$ (blue), and $\mathrm{R}_{10}$ (green), respectively). (c) Corresponding frequency sweep at $180^{\circ} \mathrm{C}$.

In the reprocessed sample $\mathrm{R}_{10}$, a small decrease in the storage modulus $\mathrm{G}^{\prime}$ of the elastic plateau modulus at $180^{\circ} \mathrm{C}$ was observed (Figure 6 c), which can again be linked to the dissociative nature of the retro aza-Michael reaction and partial reformation of the network upon reprocessing. Indeed, 
upon partial dissociation and reformation of acrylate moieties, partial homopolymerization or amidation via the re-formed secondary amines, particularly at elevated temperatures, might occur. The homopolymerization of acrylate groups was experimentally also observed in the model study (Figure S5). Nonetheless, reprocessability tests showed that this reaction barely affected the overall reprocessing properties of the herein presented networks.

\section{CONCLUSION}

In this study, beta-amino esters were demonstrated to inherently behave as dynamic moieties in CANs, with a combination of dissociative and associative dynamic behavior that is easily accessible by simply combining acrylic and amino functionalities. This concept was first demonstrated on model compounds, and then in bulk materials solely relying on dynamic (retro) aza-Michael reaction as well as for transesterification in combination with pendent hydroxyl moieties. Catalyst-free reprocessing of polyester networks was achieved with beta-positioned hydroxyl groups at $150^{\circ} \mathrm{C}$ within $30 \mathrm{~min}$. This was shown for highly crosslinked materials with varying $\mathrm{T}_{\mathrm{g}}$ ranging from elastomeric $\left(-60^{\circ} \mathrm{C}\right)$ to glassy materials $\left(90^{\circ} \mathrm{C}\right)$. The reprocessing ability of the materials was demonstrated for up to ten cycles.

This approach allows for polymer material design of tailored viscosity profiles. On the one hand, network connectivity is reduced with the dissociative part while, on the other hand, a certain degree of connectivity is maintained with the support of the associative mechanism. Yet, the thermally reversible bonds are positioned on different sides of the electrophilic center of the ester group, using different reaction mechanisms and acting synergetic. In view of the simplicity of the herein presented approach, the large amount of available building blocks, and the fact that beta-amino 
esters possess inherently thermally activated dynamic bonds, this kind of CANs are expected to contribute significantly to the current processing and recycling limitations of thermosets. Furthermore, the robustness and versatility of this system was demonstrated by combining multifunctional acrylates with amino groups on primary and secondary carbons of small or macromolecular entities. It is therefore expected to be rapidly picked up by interdisciplinary working scientists in many application areas ranging from (photocurable)coatings, adhesives, to bulk materials. Because poly(beta-amino ester) materials were explored with regard to their degradability $^{52}$, beta-amino esters might also be of importance in the end-of life recyclability and degradability of plastic materials. Lastly, this readily accessible chemistry, bridging from organic chemistry to polymer materials, invites to be used for drop-in technologies in bulk (bio)materials.

EXPERIMENTAL SECTION:

Material

Benzylalcohol ( $\geq 99 \%$ ), benzylacrylate $(\geq 99 \%$, contains hydroquinone monomethyl ether (MEHQ) as inhibitor), bisphenol A glycerolate (1 glycerol/phenol) diacrylate (contains 250 500ppm MEHQ as inhibitor), n-butylamine ( $\geq 99 \%)$, dibutylamine $(\geq 99 \%), \quad N, N-$ diisopropylethylamine (DIPEA, $\geq 99 \%$ ) 2-ethylhexylacrylate (98\%, contains MEHQ as inhibitor), 2-ethylhexylamine (98\%), $N$-methylbutylamine $(\geq 98 \%)$, pentaerythritol triacrylate (PTA, technical grade, contains 600ppm MEHQ as inhibitor), trimethylolpropane triacrylate (TMPTA, technical grade, contains 300-400ppm MEHQ as inhibitor), n-octylamine (99\%), were purchased 
from Sigma-Aldrich. Tetrahydrofuran (THF), and n-hexane were purchased from Acros Organics. 4,4'-methylenebis(cyclohexylamine) (MBCA, $>98 \%$ ) was purchased from TCI. Jeffamine D2000 was kindly provided by Huntsman, and Priamine 1074 was kindly provided by Croda. All reagents were used without further purification unless stated otherwise.

\section{Instrumentation}

Nuclear magnetic resonance (NMR) spectra were recorded on a Bruker Advance Ultrashield $300 \mathrm{MHz}$ spectrometer. Deuterated chloroform $\left(\mathrm{CDCl}_{3}\right)$ was used as the solvent in each sample. Chemical shifts are given in parts per million (ppm).

Attenuated total reflection - Fourier-transform infrared spectroscopy (ATR-FTIR) spectra were measured using a Perkin-Elmer Spectrum1000 FTIR infrared spectrometer with a diamond ATR probe.

Thermogravimetric analyses (TGA) were performed with a Mettler Toledo TGA/ SDTA851e instrument under nitrogen atmosphere at a heating rate of $10 \mathrm{~K} \cdot \mathrm{min}^{-1}$ from $25^{\circ} \mathrm{C}$ to $800{ }^{\circ} \mathrm{C}$ for the dynamic mode. Isothermal measurements were conducted under nitrogen atmosphere at $160^{\circ} \mathrm{C}$ for $120 \mathrm{~min}$ and $200{ }^{\circ} \mathrm{C}$ for $60 \mathrm{~min}$.

Differential scanning calorimetry (DSC) analyses were performed with a Mettler Toledo instrument 1/700 under nitrogen atmosphere at a heating rate of $10 \mathrm{~K} \cdot \mathrm{min}^{-1}$.

Rheology experiments were performed on an Anton Paar MCR 302. The experiments were performed in parallel plate geometry using $8 \mathrm{~mm}$ sample disks. Unless otherwise specified, the experiments were performed using a normal force of $1 \mathrm{~N}$, an oscillating frequency of $1 \mathrm{rad} . \mathrm{s}^{-1}$ and a strain of $0.1 \%$ (for materials containing tris-functional acrylates) and $1 \%$ (for materials 
containing bis-functional acrylates) was applied. For all rheology experiments, the applied stress was comprised in the linear viscoelastic region at the measured temperatures. For amplitude sweep experiments, the strain was varied from 0.01 to $100 \%$ with an oscillating frequency of $5 \mathrm{rad}^{\mathrm{sec}} \mathrm{sec}^{-}$ 1. For stress relaxation experiments, a strain of $0.1 \%$, or $1 \%$ respectively, was applied to the material and the relaxation modulus $(\mathrm{G}(\mathrm{t}))$ was followed over time at a constant temperature. The obtained characteristic relaxation time $\left(\tau^{*}\right)$ was used to calculate an activation energy. For frequency sweep measurements, a strain of $1 \%$ with a normal force of $0.2 \mathrm{~N}$ (BPAE-1), and $1 \mathrm{~N}$ (BPAE-1) was applied and a frequency range from 100 to $0.1 \mathrm{rad} . \mathrm{s}^{-1}$ was screened by following the evolution of G' and G" at a constant temperature. Creep recovery experiments were performed by applying no strain for a duration of 300s, which was followed by applying $2 \mathrm{kPa}$ shear stress for $1200 \mathrm{~s}$ and a recovery period of $1200 \mathrm{~s}$ at $80^{\circ} \mathrm{C}$ and $50^{\circ} \mathrm{C}$. Creep recovery measurements were preceded by a measurement at $80^{\circ} \mathrm{C}$ to remove a possible thermal history.

Reprocessability. To reprocess the network, the polymer was broken into pieces and placed into a rectangular mold (A: $70 \mathrm{~mm} \times 40 \mathrm{~mm} \times 2 \mathrm{~mm}$; B: $30 \mathrm{~mm} \times 15 \mathrm{~mm} \times 2 \mathrm{~mm}$ ) for compression molding. This assembly was placed in a $150^{\circ} \mathrm{C}-180^{\circ} \mathrm{C}$ preheated compression press for $1 \mathrm{~min}$ under 0.5 metric tons of pressure. Then the pressure was increased to 3 or 4 tons and kept constant for an additional $59 \mathrm{~min}$. After $60 \mathrm{~min}$ of pressing in total, the sample was carefully removed from the mold while still heated and in its elastic state. The temperature and pressing time were adjusted according to the material based on its $\mathrm{T}_{\mathrm{g}}$ and crosslinking density. Hence, highly crosslinked materials obtained using tris-functional acrylates were pressed at $180^{\circ} \mathrm{C}$ for 60 min depending on their relaxation behavior, whereas bis-acrylate based materials were pressed at $150^{\circ} \mathrm{C}$ for $30 \mathrm{~min}$. For instance: pentaerythritol triacrylate and trimethylolpropane triacrylate based networks were processed at $180^{\circ} \mathrm{C}$ for 60 min applying 3 tons (Jeffamine) or 60 min with 4 tons $\left(4,4^{\prime}-\right.$ 
methylenebis(cyclohexylamine)), whereas bisphenol A glycerolate diacrylate were pressed at $150^{\circ} \mathrm{C}$ for 30 min applying 4 tons.

Solubility tests were performed via Soxhlet extraction in refluxing THF for $24 \mathrm{~h}$ with a sample weight of around 100-200 mg. Then, the solvent was removed, and the sample was dried under vacuum for two days at $100^{\circ} \mathrm{C}$. The soluble fraction was calculated using equation (1). Swelling tests were performed by immersing a sample of $40-60 \mathrm{mg}$ in $3 \mathrm{~mL}$ THF at room temperature for seven days and the swelling ratio was calculated using equation (2). Hydrolysis tests were performed by immersing around $90 \mathrm{mg}$ of BPAE-3 in $3 \mathrm{~mL}$ demineralized water for one, four and ten days, drying the samples in a vacuum oven at $120^{\circ} \mathrm{C}$ and determining the respective soluble fraction and swelling ratio accordingly to equations (1) and (2).

$$
\text { Soluble fraction }(\%)=100 * \frac{\left(\mathrm{m}_{\mathrm{I}}-\mathrm{m}_{\mathrm{d}}\right)}{\mathrm{m}_{\mathrm{I}}}
$$

Swelling ratio $(\%)=100 * \frac{\left(\mathrm{m}_{\mathrm{S}}-\mathrm{m}_{\mathrm{I}}\right)}{\mathrm{m}_{\mathrm{I}}}$

with $\mathrm{m}_{\mathrm{i}}, \mathrm{m}_{\mathrm{s}}$ and $\mathrm{m}_{\mathrm{d}}$ being the initial, swollen and dry mass, respectively.

\section{Synthetic Procedures}

2-Ethylhexyl 3-(butyl(methyl)amino)-propanoate (1): $N$-methylbutylamine (8.53 g, 0.0979 mol, 1.2 eq.) was combined with 2-ethylhexyl prop-2-enoate (15.19 g, 0.0824 mol, 1 eq.) and stirred at $70^{\circ} \mathrm{C}$ for $72 \mathrm{~h}$. The product was then taken up in $30 \mathrm{~mL}$-hexane $(30 \mathrm{~mL})$, washed with water $(3 \mathrm{x}$ $20 \mathrm{~mL}$ ), once with brine ( $1 \times 20 \mathrm{~mL})$, and dried over $\mathrm{Mg}\left(\mathrm{SO}_{4}\right)$, after which $n$-hexane was removed and the pale yellow oil was dried in a vacuum oven over night at $40^{\circ} \mathrm{C}$. Yield $=95 \%(21.26 \mathrm{~g}$, $0.0783 \mathrm{~mol}) .{ }^{1} \mathrm{H} \mathrm{NMR}\left(300 \mathrm{MHz}, \mathrm{CDCl}_{3}, \delta \mathrm{ppm}\right): 0.82-0.95 \mathrm{~m}\left(\left(-\mathrm{CH}_{2}-\mathrm{CH}_{3}\right)_{3}\right), 1.12-1.49 \mathrm{~m}\left(\left(-\mathrm{CH}_{2}-\right.\right.$ 
$\left.\mathrm{CH}_{2}-\mathrm{CH}_{2}-\mathrm{CH}_{3}\right)\left(-\mathrm{CH}-\mathrm{CH}_{2}-\mathrm{CH}_{3}\right)\left(-\mathrm{CH}_{2}-\mathrm{CH}_{2}-\mathrm{CH}_{2}\left(\mathrm{CH}_{3}\right)\right), 1.49-1.64 \mathrm{~m}\left(\mathrm{CH}_{2}-\mathrm{CH}\left(\mathrm{CH}_{2}\right)-\mathrm{CH}_{2}\right), 2.22$ $\mathrm{s}\left(\mathrm{N}-\mathrm{CH}_{3}\right), 2.30-2.37 \mathrm{~m}\left(-\mathrm{CH}_{2}-\mathrm{CH}_{2}-\mathrm{N}\right)-, 2.43-2.50 \& 2.65-2.73 \mathrm{~m}\left(-\mathrm{N}\left(\mathrm{CH}_{3}\right)-\mathrm{CH}_{2}-\mathrm{CH}_{2}-(\mathrm{C}=\mathrm{O})-\mathrm{O}-\right)$ and $3.99\left(\mathrm{dd}, J=5.8,0.9 \mathrm{~Hz} ;\left(-(\mathrm{C}=\mathrm{O})-\mathrm{O}-\mathrm{CH}_{2}-\mathrm{CH}\left(\mathrm{CH}_{2}\right)-\mathrm{CH}_{2}-\right) .{ }^{13} \mathrm{C} \mathrm{NMR}\left(300 \mathrm{MHz}, \mathrm{CDCl}_{3}, \delta\right.\right.$ ppm) TO BE ADDED

ESI-MS m/z: [M+H] $]^{+}$for $\mathrm{C}_{16} \mathrm{H}_{33} \mathrm{NO}_{2}$; calculated: 271.2511, found: 272.300. IR (ATR platinum diamond): $v\left[\mathrm{~cm}^{-1}\right]: 2956\left(\mathrm{C}-\mathrm{CH}_{3}\right), 2929\left(\mathrm{CH}_{2}\right), 2860\left(\mathrm{C}-\mathrm{CH}_{3}\right), 2788\left(\mathrm{~N}-\mathrm{CH}_{3}\right), 1735(\mathrm{C}=\mathrm{O}), 1461$ $\left(\mathrm{CH}_{2}\right), 1379\left(\mathrm{CH}_{3}\right), 1176$ \& $1035\left(\mathrm{C}-\mathrm{O}-\mathrm{C}_{\text {ester }}\right)$.

Kinetic model study. For kinetic experiments monitoring the transesterification 1 eq. of model compound (1) (400 mg) was mixed with 12.5 eq. benzylalcohol (2 g) in a sealable glass vial, bubbled with nitrogen at room temperature and kept under nitrogen atmosphere. The vial was placed in a heated oil bath with the mixture being stirred. The kinetic experiments were performed at $80,100,110,120$, and $140^{\circ} \mathrm{C}$ for up to three days during which samples were collected from this mixture, dissolved in $\mathrm{CDCl}_{3}$ and the reaction was followed via ${ }^{1} \mathrm{H} \mathrm{NMR}$ by assessing the disappearance of the signal at $3.91 \mathrm{ppm}$ belonging to $\mathbf{1}$ which was referenced against the appearance of the signal at $3.42 \mathrm{ppm}$ related to 2-ethylhexyl alcohol. Kinetic experiments using additional tertiary amine (DIPEA), or secondary amine (dibutyl amine) as 'external' catalyst $5 \mathrm{~mol} . \%$ of the respective compound compared to $\mathbf{1}$ were added and the exchange reaction was monitored at $120^{\circ} \mathrm{C}$ for two days. For kinetic experiments monitoring the dynamic aza-Michael reaction 1 eq. of model compound (1) $(400 \mathrm{mg})$ was mixed with 6 eq. benzylacrylate $(1.43 \mathrm{~g})$ in a sealable glass vial, bubbled with nitrogen at room temperature and kept under nitrogen atmosphere. The vial was placed in a heated oil bath with the mixture being stirred. The kinetic experiments were performed at $100,130,140,150$, and $160^{\circ} \mathrm{C}$ for up to two days during which samples were collected from this mixture, dissolved in $\mathrm{CDCl}_{3}$ and the reaction was followed via ${ }^{1} \mathrm{H}$ NMR by 
assessing the disappearance of the signal at $4.02 \mathrm{ppm}$ belonging to 1 which was referenced against the appearance of the signal at $4.10 \mathrm{ppm}$ related to 2-ethylhexylacrylate. Following the assumption of a stationary state, consequently mimicking a first order reaction, the kinetic reaction constants $(\mathrm{k})$ were derived from the slope of the linear decay of the first few points of time. The logarithmic reaction constants $(\ln (\mathrm{k}))$ were then plotted against $1000 . \mathrm{T}^{-1}$ in an Arrhenius plot to compare the relative temperature dependent behavior. An activation energy was calculated from the obtained slope by equation (3). ${ }^{26}$

$$
\ln (\mathrm{k})=-\frac{E_{a}}{\mathrm{RT}}
$$

Network synthesis. For the herein investigated materials the multifunctional acrylate and the multifunctional primary amino compounds were weighted with a ratio of acrylate to primary amine moieties of 1:0.5 and mixed in a polypropylene cup using a DAC 150.1 FVZ speed mixer (typical conditions of mixing: 2 min with a speed of $2500 \mathrm{rpm}$ ) targeting 3 to $10 \mathrm{~g}$ of resulting material. When 4,4'-methylenebis(cyclohexylamine) was used, the sample was allowed to warm up to $70^{\circ} \mathrm{C}$ in an oven in order to melt the amine. Similarly, when bisphenol A glycerolate diacrylate was used the sample was warmed up in an oven at $70^{\circ} \mathrm{C}$ to lower the viscosity of the acrylate for facilitated mixing. Then, the plastic cup was placed in an oven at $70^{\circ}-80^{\circ} \mathrm{C}$ for $48-72 \mathrm{~h}$ to complete the network formation. Hereafter, the polypropylene vial was broken, the sample was removed, broken into pieces, and pressed separately in steel molds, following the aforementioned reprocessing procedures.

TOC-Figure: 


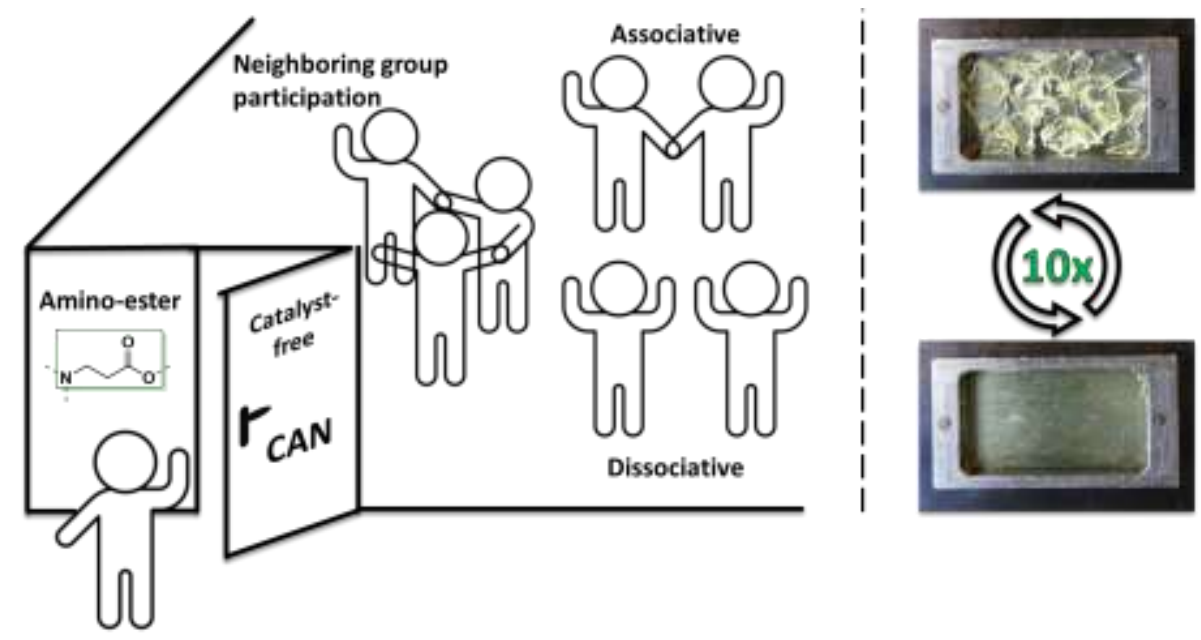

\section{BRIEFS:}

This study describes the exploration of the aza-Michael adduct of an amine and an acrylate as a versatile building block for the straightforward creation of catalyst-free covalent adaptable networks.

\section{ASSOCIATED CONTENT}

Supporting Information. Containing NMR spectra, kinetics plots, IR spectra, DSC and TGA thermograms, stress relaxation data, frequency sweeps, and images of reprocessed materials.

\section{AUTHOR INFORMATION}

\section{Corresponding Author}

* Filip E. Du Prez: filip.duprez@ugent.be

\section{Author Contributions}

The manuscript was written through contributions of all authors. All authors have given approval to the final version of the manuscript. 


\section{Notes}

The authors declare no competing financial interest.

\section{ACKNOWLEDGMENT}

We would like to thank Bernhard de Meyer for technical support, Prof. Dr. Johan M. Winne, Dr. Joshua O. Holloway, Dr. Lucas Stricker, Dr. Nezha Badi, and Kâmil Ünal for fruitful discussions. C.T. and M.G. acknowledge the Research Foundation-Flanders (FWO) for Ph.D. (1S27920N) and Postdoctoral (12Y9918N) fellowships. F.D.P. thanks BOF-UGent (GOA-funding).

\footnotetext{
ABBREVIATIONS

BAE-\#, beta-amino ester network; BPAE-\#, bisphenol A beta-amino ester network; CAN, covalent adaptable network; $\mathrm{CDCl}_{3}$, deuterated chloroform; DIPEA, $N, N$-diisopropylethylamine;

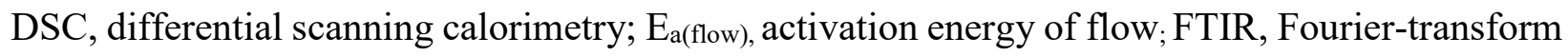
infrared spectroscopy; NGP, neighboring group participation; NMR, nuclear magnetic resonance spectroscopy; PTA, pentaerythritol triacrylate; TGA, thermogravimetric analyses; $\mathrm{T}_{\mathrm{g}}$, glass transition temperature; THF, tetrahydrofuran; TMPTA, trimethylolpropane triacrylate.
} 


\section{REFERENCES}

(1) Horejs, C. Nat Rev Mat 2020, 5, 641.

(2) Billiet, S.; Trenor, S. R. ACS Macro Lett. 2020, 9, 1376.

(3) Patrick, J. F.; Robb, M. J.; Sottos, N. R.; Moore, J. S.; White, S. R. Nature 2016, $540,363$.

(4) Chen, X.; Dam, M. A.; Ono, K.; Mal, A.; Shen, H.; Nutt, S. R.; Sheran, K.; Wudl, F. Science 2002, 295, 1698.

(5) Scott, T. F.; Schneider, A. D.; Cook, W. D.; Bowman, C. N. Science 2005, 308, 1615.

(6) Montarnal, D.; Capelot, M.; Tournilhac, F.; Leibler, L. Science 2011, 334, 965.

(7) Zou, W.; Dong, J.; Luo, Y.; Zhao, Q.; Xie, T. Adv. Mater. 2017, 29, 1606100.

(8) Tobolsky, A. V.; Stern, M. D. Rubber Chem. Technol. 1946, 19, 1178.

(9) Zheng, P.; McCarthy, T. J. J. Am. Chem. Soc. 2012, 134, 2024.

(10) Bowman, C. N.; Kloxin, C. J. Angew. Chem. Int. Ed. Engl. 2012, 51, 4272.

(11) McBride, M. K.; Worrell, B. T.; Brown, T.; Cox, L. M.; Sowan, N.; Wang, C.; Podgorski, M.; Martinez, A. M.; Bowman, C. N. Annu Rev Chem Biomol Eng 2019, 10, 175.

(12) Fortman, D. J.; Brutman, J. P.; De Hoe, G. X.; Snyder, R. L.; Dichtel, W. R.; Hillmyer, M. A. ACS Sustainable Chem. Eng. 2018, 6, 11145.

(13) Terryn, S.; Brancart, J.; Lefeber, D.; Van Assche, G.; Vanderborght, B. Sci Robot 2017, 2, eaan4268.

(14) Chapelle, C.; Quienne, B.; Bonneaud, C.; David, G.; Caillol, S. Carbohydr. Polym. 2021, 253, 117222 .

(15) Rekondo, A.; Martin, R.; Ruiz de Luzuriaga, A.; Cabañero, G.; Grande, H. J.; Odriozola, I. Mater. Horiz. 2014, 1, 237.

(16) Ruiz de Luzuriaga, A.; Martin, R.; Markaide, N.; Rekondo, A.; Cabañero, G.; Rodríguez, J.; Odriozola, I. Mater. Horiz. 2016, 3, 241.

(17) Lei, Z. Q.; Xiang, H. P.; Yuan, Y. J.; Rong, M. Z.; Zhang, M. Q. Chem. Mater. 2014, 26, 2038.

(18) Fortman, D. J.; Snyder, R. L.; Sheppard, D. T.; Dichtel, W. R. ACS Macro Lett. 2018, 7, 1226.

(19) Nishimura, Y.; Chung, J.; Muradyan, H.; Guan, Z. J. Am. Chem. Soc. 2017, 139, 14881.

(20) Tretbar, C. A.; Neal, J. A.; Guan, Z. J. Am. Chem. Soc. 2019, 141, 16595.

(21) Obadia, M. M.; Mudraboyina, B. P.; Serghei, A.; Montarnal, D.; Drockenmuller, E. J. Am. Chem. Soc. 2015, 137, 6078.

(22) Obadia, M. M.; Jourdain, A.; Cassagnau, P.; Montarnal, D.; Drockenmuller, E. Adv. Funct. Mater. 2017, 27, 1703258.

(23) Hendriks, B.; Waelkens, J.; Winne, J. M.; Du Prez, F. E. ACS Macro Lett. 2017, 6, 930.

(24) Capelot, M.; Montarnal, D.; Tournilhac, F.; Leibler, L. J. Am. Chem. Soc. 2012, $134,7664$.

(25) Wang, C.; Goldman, T. M.; Worrell, B. T.; McBride, M. K.; Alim, M. D.; Bowman, C. N. Mater. Horiz. 2018, 5, 1042.

(26) Guerre, M.; Taplan, C.; Nicolay, R.; Winne, J. M.; Du Prez, F. E. J. Am. Chem. Soc. 2018, 140, 13272. 
(27) Denissen, W.; Rivero, G.; Nicolaÿ, R.; Leibler, L.; Winne, J. M.; Du Prez, F. E. Adv. Funct. Mater. 2015, 25, 2451.

(28) Taplan, C.; Guerre, M.; Winne, J. M.; Du Prez, F. E. Mater. Horiz. 2020, 7, 104.

(29) Taynton, P.; Ni, H.; Zhu, C.; Yu, K.; Loob, S.; Jin, Y.; Qi, H. J.; Zhang, W. Adv. Mater. 2016, 28, 2904.

(30) Whiteley, J. M.; Taynton, P.; Zhang, W.; Lee, S. H. Adv. Mater. 2015, 27, 6922.

(31) Taplan, C.; Guerre, M.; Bowman, C. N.; Du Prez, F. E. Macromol. Rapid Commun., $n / a, 2000644$.

(32) Jin, K.; Li, L.; Torkelson, J. M. Adv. Mater. 2016, $28,6746$.

(33) Fortman, D. J.; Brutman, J. P.; Cramer, C. J.; Hillmyer, M. A.; Dichtel, W. R. J. Am. Chem. Soc. 2015, 137, 14019.

(34) Snyder, R. L.; Fortman, D. J.; De Hoe, G. X.; Hillmyer, M. A.; Dichtel, W. R. Macromolecules 2018, 51, 389.

(35) Lu, Y. X.; Tournilhac, F.; Leibler, L.; Guan, Z. J. Am. Chem. Soc. 2012, 134, 8424.

(36) Rottger, M.; Domenech, T.; van der Weegen, R.; Breuillac, A.; Nicolay, R.; Leibler, L. Science 2017, 356, 62 .

(37) Zhang, B.; Digby, Z. A.; Flum, J. A.; Chakma, P.; Saul, J. M.; Sparks, J. L.; Konkolewicz, D. Macromolecules 2016, 49, 6871.

(38) Scheutz, G. M.; Lessard, J. J.; Sims, M. B.; Sumerlin, B. S. J. Am. Chem. Soc. 2019, $141,16181$.

(39) Van Zee, N. J.; Nicolaÿ, R. Prog. Polym. Sci. 2020, 104, 101233.

(40) Podgorski, M.; Fairbanks, B. D.; Kirkpatrick, B. E.; McBride, M.; Martinez, A.; Dobson, A.; Bongiardina, N. J.; Bowman, C. N. Adv. Mater. 2020, 32, 1906876.

(41) Guerre, M.; Taplan, C.; Winne, J. M.; Du Prez, F. E. Chem. Sci. 2020, 11, 4855.

(42) Winne, J. M.; Leibler, L.; Du Prez, F. E. Polym. Chem. 2019, 10, 6091.

(43) Van Lijsebetten, F.; Holloway, J. O.; Winne, J. M.; Du Prez, F. E. Chem. Soc. Rev. $2020,49,8425$.

(44) Delahaye, M.; Winne, J. M.; Du Prez, F. E. J. Am. Chem. Soc. 2019, 141, 15277.

(45) Zhang, H.; Majumdar, S.; van Benthem, R. A. T. M.; Sijbesma, R. P.; Heuts, J. P. A. ACS Macro Lett. 2020, 9, 272.

(46) Delahaye, M.; Tanini, F.; Holloway, J. O.; Winne, J. M.; Du Prez, F. E. Polym. Chem. 2020, 11, 5207.

(47) Podgorski, M.; Mavila, S.; Huang, S.; Spurgin, N.; Sinha, J.; Bowman, C. N. Angew. Chem. Int. Ed. Engl. 2020, 59, 9345.

(48) Chen, M.; Zhou, L.; Wu, Y.; Zhao, X.; Zhang, Y. ACS Macro Lett. 2019, 8, 255.

(49) Podgórski, M.; Spurgin, N.; Mavila, S.; Bowman, C. N. Polym. Chem. 2020, 11, 5365.

(50) Van Herck, N.; Maes, D.; Unal, K.; Guerre, M.; Winne, J. M.; Du Prez, F. E. Angew. Chem. Int. Ed. Engl. 2020, 59, 3609.

(51) Elling, B. R.; Dichtel, W. R. ACS Cent Sci 2020, 6, 1488.

(52) Anderson, D. G.; Tweedie, C. A.; Hossain, N.; Navarro, S. M.; Brey, D. M.; Van Vliet, K. J.; Langer, R.; Burdick, J. A. Adv. Mater. 2006, 18, 2614.

(53) Lynn, D. M.; Langer, R. J. Am. Chem. Soc. 2000, 122, 10761.

(54) Genest, A.; Portinha, D.; Fleury, E.; Ganachaud, F. Prog. Polym. Sci. 2017, 72, 61.

(55) González, G.; Fernández-Francos, X.; Serra, À.; Sangermano, M.; Ramis, X. Polym. Chem. 2015, 6, 6987. 
(56) Zhang, H.; Bre, L. P.; Zhao, T.; Zheng, Y.; Newland, B.; Wang, W. Biomaterials 2014, 35, 711.

(57) Baruah, R.; Kumar, A.; Ujjwal, R. R.; Kedia, S.; Ranjan, A.; Ojha, U. Macromolecules 2016, 49, 7814.

(58) Stukenbroeker, T.; Wang, W.; Winne, J. M.; Du Prez, F. E.; Nicolaÿ, R.; Leibler, L. Polym. Chem. 2017, 8, 6590 .

(59) Altuna, F. I.; Hoppe, C. E.; Williams, R. J. J. Eur. Polym. J. 2019, 113, 297.

(60) Li, L.; Chen, X.; Jin, K.; Rusayyis, M. B.; Torkelson, J. M. Macromolecules 2021, $54,1452$.

(61) Jourdain, A.; Asbai, R.; Anaya, O.; Chehimi, M. M.; Drockenmuller, E.; Montarnal, D. Macromolecules 2020, 53, 1884. 